\title{
Orgulho e preconceito e Zumbis: uma versão de Jane Austen para o público juvenil contemporâneo
}

\section{Pride and Prejudice and Zombies: a version of Jane Austen's classic for contemporary youngsters}

\author{
Fabiane Verardi Burlamaque* \\ Bianca DeOn Rossato**
}

Resumo: Por meio das teses de Henry Jenkins (2006) sobre cultura participatória, e de Teresa Colomer (2003) sobre literatura juvenil, este artigo visa investigar como se dá a recriação da obra Orgulho e preconceito na versão Orgulho e Preconceito e Zumbis (2010A), de Seth Grahame-Smith, e como tal derivativo pode ser um meio para aproximar os jovens leitores dos clássicos.

Abstract: Through the concepts of participatory culture, by Henry Jenkins (2006), and of juvenile literature, by Teresa Colomer (2003), this paper aims to investigate how the classic Pride and Prejudice (1813) by Jane Austen is recreated into Pride and Prejudice and Zombies (2010a) by Seth Grahame-Smith, and how such derivative may become a way FOR - BRINGING young readers CLOSER to the classics.

Palavras-chave: Literatura Juvenil, Orgulho e Preconceito; Derivativos, Cultura participatória, Orgulho e Preconceito e Zumbis.

Keywords: Juvenile Literature, Pride and Prejudice, Derivatives, Participatory Culture, Pride and Prejudice and Zombies.

\footnotetext{
* Doutora em Letras (PUCRS) e Professora Titular I do Curso de Letras e do Programa de PósGraduação em Letras da Universidade de Passo Fundo.

** Doutoranda em Letras UFRGS. Professora do Instituto Federal de Educação, Ciência e Tecnologia do Rio Grande do Sul - IFRS.
} 
"É uma verdade universalmente aceita..." Assim inicia a obra de Jane Austen - publicada em 1813 - cujos leitores ardorosos esperam deparar-se com o seguinte: "que um homem solteiro de posse de certa fortuna, deve estar à procura de uma esposa". (Austen, 2009, p. 9). E, a partir dela, seguiria uma narrativa de sutil ironia sobre as relações humanas. Contudo, não é Orgulho e preconceito o livro ao qual se procederá a análise e, sim, Orgulho e preconceito e zumbis, de Seth Grahame-Smith, publicado em 2009 e traduzido para o português em 2010. Portanto, o final para aquela sentença é: "que um zumbi, uma vez de posse de um cérebro, necessita de mais cérebros". (Grahame-Smith, 2010a, p. 8). E a expectativa do leitor, já antes subvertida pela presença do termo zumbis no título da obra, é totalmente desmistificada pela frase de abertura.

$\mathrm{O}$ autor americano Seth Grahame-Smith utiliza praticamente o enredo inteiro criado por sua antecessora inglesa duzentos anos antes para criar o que se convencionou chamar de mashup ${ }^{1}$ literário. Sua tarefa é a de ajustar a presença dos zumbis de modo que a trama, mesmo que tomando outro formato, não perca um fio condutor coerente. Com fins a compreender melhor que tipo de obra é o mashup em análise, é fundamental que se observe o momento atual nas relações entre produção e consumo de literatura. Os últimos dez ou quinze anos foram palco de inúmeros avanços e transformações, especialmente devido à propagação da internet e do acesso rápido à informação. No que se refere à literatura, John Ladd - estudioso da convergência entre poesia e tecnologia, escritor e poeta - constata que "a leitura e a escrita de poesia e ficção hoje é completamente diferente do que há dez ou mesmo cinco anos atrás" (Ladd, 2010). Contudo, segundo o teórico, a sociedade despendeu muito mais tempo preocupando-se com tais transformações na área do jornalismo enquanto que "o modo como lemos e discutimos o trabalho criativo mudou completamente sem que se fizesse tanto alarde" (Ladd, 2010). Assim, quando obras polêmicas são lançadas, o impacto parece ser muito maior do que se esperaria, especialmente, no que concerne à reação de críticos literários.

As modificações na produção e na compreensão da produção literária, conforme Ladd constata, são influenciadas pelo fenômeno da internet e sua natureza

\footnotetext{
${ }^{1}$ Outras produções contemporâneas são o sampling, o copy-and-paste e a fanfiction (SANTANA, 2012).
} 
participatória ${ }^{2}$ tornando não somente muito fácil, mas talvez inútil elaborar um comentário acerca de uma obra, na medida em que todos têm acesso às produções e são livres para dialogar com tais trabalhos na rede mundial de computadores. Henry Jenkins estabelece que "a cultura participatória é uma cultura com relativamente poucas barreiras à produção artística" (Jenkins, 2010), assim como a reflexão a seu respeito. Nesse sentido, "o que antes permanecia nos limites de um grupo seleto de artistas, críticos e acadêmicos, está disponível ao público em geral" (Ladd, 2010). Tal movimentação da literatura e a aparente perda de controle sobre o que é produzido e como é recebido pelo público têm feito o "sangue de alguns literatos puristas ferver". Percebe-se que a posição do leitor, no contexto acima referido, extrapola a condição de mero leitor/receptor de um texto criativo. Neste novo meio de socialização de informações, o leitor, especialmente o jovem leitor, não só se apropria do texto, mas tem espaço para expressar seu horizonte axiológico e dialogar com a produção artística, podendo, ainda, compartilhar essa visão com outros leitores que assumem, também, a posição de críticos.

É válido registrar brevemente em que consiste uma obra mashup. O termo provém das áreas da tecnologia da informática e se refere ao recorte de elementos de fontes distintas e seu agrupamento para outra finalidade. Nas áreas da música e do vídeo, esse fenômeno ${ }^{3}$ também se faz presente nos últimos anos e é essencialmente produto de usuários de aplicativos de computador e não é desenvolvido por grandes empresas da comunicação, conforme afirma Henry Jenkins (2010). Segundo a definição encontrada no site www.mashmashup. com, esse tipo de trabalho se constitui em misturas de elementos de diversas fontes distintas para formar uma nova composição. $O$ termo também pode ser explicado como literatura remixada. Segundo o próprio autor do romance, em uma entrevista extraída do website The Varsity, seu trabalho é "um tipo de equivalente literário do mashup ou remix do YouTube" (Grahame-Smith, 2010b). Tal estrutura narrativa encontra no público jovem um excelente receptor, pois, ao

\footnotetext{
2 Para maior aprofundamento na questão da cultura participatória, ver JENKINS, Henry. Convergence Culture: where the old and new media collide. New York: NYU, 2006.

${ }^{3} \mathrm{Um}$ estudo mais aprofundado revela que as origens de produtos mashup estão nas técnicas artísticas utilizadas desde o evento do Modernismo nas artes, como o dadaísmo, o cubismo, o grupo fluxos, além da pop art que fazem amplo uso da montagem, colagem e bricolagem (Santana, 2012).
} 
tratar de temas que são do interesse dos jovens contemporâneos, beneficia uma aproximação entre autores e leitores.

Em relação ao destinatário da literatura juvenil, Teresa Colomer (2003) destaca que, desde os fins da década de 1970, a literatura infantil e juvenil experimentou um "enorme impulso inovador para adequar-se às características de seu público atual" (Colomer, 2003, p. 173), que demanda "importantes mudanças em relação à narrativa anterior, nos critérios dos autores sobre o que é adequado e pertinente, nos temas que abordam em suas narrativas, na descrição do mundo que oferecem e nos valores que propõem" (Colomer, 2003, p. 174).

Ao proceder-se à análise da obra percebe-se que o diálogo estabelecido pelo autor americano com a narrativa original proporciona ao leitor uma completa inversão de perspectiva, contudo sem alterar definitivamente o desfecho das intrigas existentes na obra. Os zumbis entram na rotina da sociedade inglesa do período regencial e juntamente com eles tudo o que se julga necessário para o seu combate. Dentre eles, destacam-se as artes marciais - uma provável referência aos filmes de kung fu dos anos 80 -, que são estudadas no Japão por aqueles que provêm das classes abastadas e na China pelos menos afortunados. É da fala e do comportamento de Lady Catherine que se depreende tal estratificação social no que tange às artes marciais. Quando Catherine desafia Elizabeth a lutar com cinco de seus melhores ninjas e a moça venda seus olhos, em uma "atitude desafiadora", a velha senhora diz: "Srta. Bennet, gostaria de lembrá-la que lhe falta uma formação apropriada como guerreira. Seu mestre foi um monge chinês. Já esses ninjas procedem dos melhores dojos japoneses" (Grahame-Smith, 2010a, p. 129).

Uma vez que alguns personagens passam longas temporadas no Japão e na China e incorporam, não somente as artes marciais, mas também certos valores, como disciplina, retidão e honestidade, vê-se que os espaços da trama também sofrem influência dos elementos orientais. As casas de família que possuem aprendizes das artes possuem dojos - espaços que reproduzem os reais dojos orientais, nos quais se exercitam as técnicas de combate. As grandes mansões dos nobres possuem decorações e mobília provenientes daquela parte do globo. Um exemplo é a descrição da mansão de Pemberley, na qual reside o Sr. Darcy, e de sua governanta, feita pelo narrador quando Elizabeth e o Sr. e a Sra. Gardiner passeiam pela residência: 
Veio a governanta; uma senhora com uma respeitável aparência inglesa, vestida num quimono e arrastando seus pés atados, conforme a tradição oriental. Seguiram-na até um salão de jantar. Era um ambiente amplo e bem proporcionado, belamente decorado com objetos de arte e mobiliário oriundos do Japão tão amado do Sr. Darcy (Grahame-Smith, 2010a, p. 194).

Tais caracterizações contribuem para o estabelecimento de uma coerência no romance, uma vez que reforçam a interferência dos zumbis na trama, considerando-se que as artes marciais e os elementos orientais surgem exatamente devido à presença das criaturas. É curioso observar, no entanto, que a governanta possua "uma respeitável aparência inglesa", uma vez que está "vestida num quimono e arrastando seus pés atados, conforme a tradição oriental". Não só a vestimenta como também seu modo de andar remetem aos costumes orientais. Onde reside, então, a aparência inglesa? Talvez o narrador esteja se referindo à aparência física e a expressão em seu rosto, embora isso não fique claro. De qualquer modo, é perceptível o elemento cômico implícito no jogo de ideias expressado pelo narrador, uma vez que os ingleses tornaram-se conhecidos por seu notável espírito conservador.

Ainda no que se refere à influência do elemento oriental, observa-se que até mesmo as moças em idade de se casarem possuem mais um requisito a ser levado em consideração. Agora, além de possuírem dotes para a música, canto e dança, assim como bordado e costura, as senhoritas inglesas precisam dominar as artes marciais para combater a praga. Sua Majestade dá-lhes a dispensa no momento em que se casam. Como já fora mencionado, a distinção de classes também é considerada no que se refere às habilidades de combate, uma vez que se julgam melhores treinados aqueles que tiveram seus estudos realizados no Japão. Nesse sentido, observa-se que os treinamentos pelos quais as moças da família Bennet adquiriram suas habilidades de combate foram na China. Entretanto, as filhas mais velhas, Jane e Elizabeth, mesmo tendo aprendido as técnicas chinesas, demonstram maior capacidade de disciplina e estudo e, portanto, desempenham mais efetivamente sua função de caçadoras de zumbis enquanto que as mais novas, Mary, Lydia e Kitty, por não se dedicarem, não possuem grande habilidade. Consequentemente, Jane e Elizabeth, não só são mais valorizadas por serem mais sensatas e recatadas, mas também por obterem mais sucesso nos enfrentamentos com zumbis. Portanto, embora sob outra perspectiva, a va- 
loração das personagens Jane e Elizabeth no romance contemporâneo é a mesma a elas atribuída na obra original.

No que tange à questão do casamento, tema central do romance original, constata-se que sua condição não é destituída de importância na trama contemporânea, mas que compartilha espaço com os comedores de cérebros. Além disso, o desenrolar dos eventos, que culminam, no final da obra, com o casamento de Bingley e Jane e o de Darcy e Elizabeth, é diretamente perturbado pela presença das criaturas. Tal observação é exemplificada nas cenas que apresentam a interferência de Darcy no afastamento de Bingley de Netherfield Park. Na trama original, Darcy engendra o afastamento de Bingley porque considera a família de Jane de classe inferior e, principalmente, por pensar que ela estivesse indiferente aos sentimentos do jovem. Já na obra do escritor americano, Darcy convence Bingley a voltar a Londres por pensar que a Srta. Bennet está infectada pela praga dos zumbis. No entanto, o próprio Darcy verifica que a doença que afligiu a senhorita era, de fato, apenas um forte resfriado acompanhado de febre. Darcy assim relata a Elizabeth:

No entanto, não foi senão depois que ela adoeceu e ficou hospedada em Netherfield que senti qualquer apreensão a esse respeito. Por saber de sua atividade como exterminadora de mortos-vivos, fiquei convencido de que ela havia sido infectada pela estranha praga [e que] logo ela iniciaria seu infeliz descanso para a condição de serva de Satã. (Grahame-Smith, 2010a, p. 155-156)

A atitude do Sr. Darcy com relação à Jane provocou a ira de Elizabeth que, a fim de manter a honra da irmã intacta e trazer-lhe de volta o ânimo, "decidiu que agarraria o coração do Sr. Darcy, ainda pulsante, entre os dedos, antes de encerrar sua temporada em Kent" (Grahame-Smith, 2010a, p. 146). Seus ensinamentos de guerreira não a permitem ter piedade diante da maldade daquele cavalheiro e a única coisa a se fazer, a fim de que se obtenha justiça, é matá-lo. Mais adiante, ao reler as cartas de Jane, em busca de maiores evidências acerca do padecimento da irmã, acalma-a o fato de "pensar que ele logo tombaria pela ponta de sua espada - e que em menos de quinze dias ela estaria de novo com Jane, podendo, então, ajudá-la a recuperar o ânimo, a começar por lhe apresentar o coração e a cabeça do Sr. Darcy" (Grahame-Smith, 2010a, p. 147). Verifica-se uma subversão do pensamento no que se refere à questão do feminino do 
período regencial inglês. Grahame-Smith apresenta uma mulher com traços de personalidade que seriam atribuídos a um homem, como a raiva que a faz sentir desejo de ver um inimigo morto.

Talvez de forma exagerada, Grahame-Smith insira na trama austeniana não somente seus próprios juízos de valor, mas o horizonte axiológico de seu tempo, embora não os permita subverter por completo o desfecho do romance. A muIher representada por Elizabeth revela-se capaz de conduzir seu próprio destino, alterando-o conforme lhe é conveniente. Já no romance original, a protagonista se ressalta por sua personalidade forte e decidida - como quando se recusa a casar com o Sr. Collins. A trama contemporânea mantém esse aspecto, atribuindo a ela um elemento que a equipara ao homem, qual seja, a ânsia de ver um inimigo derrotado. Assim, Grahame-Smith aborda uma questão cada vez mais verificável no universo feminino contemporâneo: a busca pela igualdade social entre homens e mulheres. Ao realizar uma análise exaustiva dos romances juvenis contemporâneos espanhóis, Colomer constatou que "os gêneros literários analisados têm uma presença quantitativa muito homogênea entre as narrativas para adolescentes" (Colomer, 2003, p. 248). A temática explorada por Grahame-Smith no que tange aos papéis de igualdade entre homens e mulheres vai ao encontro do que é discutido e verificado pela estudiosa espanhola.

Ainda relacionado à temática do casamento, o fato que merece destaque é a união entre Charlotte Lucas - grande amiga de Elizabeth Bennet - e o Sr. Collins. Na trama de Austen, a moça aceita casar-se com o pastor, mesmo ele tendo sido recusado por sua outra grande amiga Lizzy, apenas alguns dias antes. Solteira aos vinte e sete anos e proveniente de família de poucas posses, a Srta. Lucas não tem muitas opções e já se tornou um peso para os pais. Assim, mesmo descrevendo o Sr. Collins como um homem "nem sensato nem agradável", aceita casar-se com ele, uma vez que o importante em sua concepção é o estar casada, pouco importando o homem ou o relacionamento em si (Austen, 2009, p. 105). O enredo de Grahame-Smith aborda a situação de Charlotte sob outra visão: Charlotte foi infectada pela praga e não goza de muito tempo de vida. Assim, Collins representa sua última chance de casar-se, ter sua própria residência e ser feliz no matrimônio.

Duas possibilidades de investigação despontam de tal situação: a primeira delas consiste em uma possível inferência feita pelo autor contemporâneo. Ao apresentar Charlotte Lucas, aos vinte e sete anos - já é considerada uma soltei- 
rona para os padrões do período regencial inglês -, infectada por uma praga e, por isso, aceitando casar-se por interesse e não por amor, Grahame-Smith talvez infira que na trama original ela houvesse aceitado casar-se com aquele homem ridículo por não ser mais pura, ou seja, virgem, o que para a época destruiria a reputação da moça mais bem afortunada. Esse é certamente um posicionamento arriscado, haja vista não se verificar dados indicativos suficientes dessa possibilidade. A segunda é a ridicularização extrema de Collins e de todos ao seu redor, uma vez que Elizabeth é a única pessoa esperta o suficiente para verificar que a Sra. Collins está transformando-se em um zumbi. Nem mesmo Darcy ou Lady Catherine conseguem perceber e tampouco seu marido Collins, que nesta situação é rebaixado à estupidez extrema.

É válido ressaltar que, conforme Bakhtin, ao se apropriar dos "falares" alheios, o prosador não transforma ou modifica a diversidade social a eles pertencente, mas as mantém a uma distância necessária do enredo central de suas obras, de suas intenções pessoais. No caso de Orgulho e preconceito e zumbis, o que parece acontecer é que seu autor deixa os zumbis, por ele inseridos na trama, a certa distância do enredo original, de modo que se os percebe no meio do caminho entre a narrativa original, da escritora inglesa, e as reais expectativas de Grahame-Smith. Tal referência pode ser depreendida da constatação de que os zumbis perturbam por diversos momentos o desenrolar dos fatos, mas apenas a vida de Charlotte e a de Collins são definitivamente afetadas pelos zumbis, uma vez que ele é obrigado a decapitar sua esposa e, em seguida, suicida-se. Já o desfecho que se constitui no casamento das irmãs Jane e Elizabeth Bennet com os cavalheiros Bingley e Darcy permanece intacto. Talvez esta seja uma estratégia do autor contemporâneo a fim de não romper completamente os laços afetivos dos leitores tradicionais de Jane Austen, embora muitos já manifestem seu choque com tal transformação imposta à obra original.

O Sr. Collins é a mais contundente representação da acentuação do ridículo na trama de Grahame-Smith. Na obra de Austen, através do discurso da protagonista, Elizabeth Bennet, percebe-se que Collins é um homem não usual, de comportamento excessivamente formal, e muitas vezes desprovido de bom senso, o que o ridiculariza diante dos demais. Ao manter Collins ignorante sobre o estado de sua esposa, mesmo quando ela apresenta sinais claros de contágio, o escritor contemporâneo intensifica a estupidez do homem. É dos pensamentos de Elizabeth que se percebem tais constatações: 
No entanto, quando a Sra. Collins deu as boas vindas a Elizabeth, esta ficou extremamente consternada com a aparência da amiga. Fazia meses que não se viam, e aqueles não haviam sido meses generosos, pois a pele de Charlotte agora estava cinzenta e coberta de ferimentos, além de ela demonstrar grande esforço para falar. Que ninguém entre os demais reparasse nisso, Elizabeth atribuía-o à estupidez de todos - particularmente do Sr. Collins que aparentemente não tinha a menor ideia de que sua mulher estava três quartos morta (Grahame-Smith, 2010a, p. 119).

A ignorância daqueles que cercam Charlotte de sua real condição fica evidente em um dos jantares por ela frequentado em Rosings Park, residência de Lady Catherine de Bourgh: "Depois de derramar a terceira xícara de chá no colo, Charlotte levantou-se, pedindo licença para deixar a outra mesa, apertando o estômago e estampando no rosto intensa dor. - Peshhho que me dessssculpe.... Sua....Ssssenho...ia..." (Grahame-Smith, 2010a, p. 127). A seguir, sendo quase ignorada por todos, exceto por Elizabeth, Charlotte "caminhou, mancando, até o canto mais distante da sala, onde arregaçou a saia e agachou-se, ficando de cócoras" (Grahame-Smith, 2010a, p. 127). A imagem criada pelo escritor americano já permite que se depreenda o efeito cômico, de riso, embora a situação de Charlotte seja trágica. A descrição seguinte, do mal que afligia a personagem naquela noite, completa a cena, quebrando inteiramente a expectativa com relação ao romance original:

Elizabeth prontamente pediu licença, levantou-se da cadeira e agarrou Charlotte pelo braço, tomando cuidado para não chamar atenção, e arrastou-a até o toalete, onde ficou ao lado de sua infectada amiga, que teve de sofrer todo um quarto de hora com uma diarréia tão intensa que o decoro impede que seja descrita nessas páginas (Grahame-Smith, 2010a, p. 127).

Nem mesmo o narrador da trama se permite relatar o que sucedeu a Charlotte em tal episódio, tamanha é a sensação de repugnância provocada pela cena. $\mathrm{E}$, no entanto, seu esposo, na intimidade do lar não é capaz de perceber as transformações diárias sofridas por sua esposa. A figura de Charlotte representa o ápice da subversão provocada por Grahame-Smith no romance original, que lhe permite manter uma unidade. $O$ autor parece ter observado na caracterização 
da personagem um espaço para dialogar com o texto austeniano, permitindo-se não só expor aquilo que está dentro de seu horizonte axiológico, mas também manter a coerência de sua obra, uma vez que é permeada por zumbis.

Percebe-se, também, na obra de Grahame-Smith o fato de as diferenças de classe social não terem importância alguma para os zumbis, assim como o fato de, tanto pessoas da alta sociedade quanto trabalhadores e pessoas humildes, sucumbirem aos ataques dos mortos-vivos. Constatação essa que permite inferir a intenção do autor de criticar as barreiras impostas pelas diferenças de classe. Tal crítica acaba explicitada na obra de forma indireta, através do cômico e do riso, na medida em que são apresentadas situações de ridicularização dos personagens. $\mathrm{O}$ autor deixa implícito que as pessoas, antes de serem provenientes desta ou daquela classe social, são seres humanos que estão inseridos no mesmo contexto e que podem estar sujeitos aos mesmos perigos. Até mesmo as diferenças entre o campo e a cidade são arrefecidas pela presença dos zumbis. Em uma discussão entre a Sra. Bennet e o Sr. Darcy sobre qual seria melhor, o campo ou a cidade, a senhora defende o campo, ao contrário de Darcy que o considera monótono. Ela afirma: "Exceto, é claro, quando o interior é invadido pelos mesmos não mencionáveis que infestam a capital" (Grahame-Smith, 2010a, p. 37). Ou seja, a praga atinge a todos sem distinção.

As imagens singulares proporcionadas pelas descrições dos exercícios e posições de combates praticados pelos guerreiros atribuem comicidade a personagens que, na trama original, são valorizados por suas personalidades transparecerem seriedade e austeridade, como no caso de Elizabeth Bennet e do Sr. Darcy. A cena, na sala de Netherfield, na qual Darcy está a escrever e Caroline Bingley convida Elizabeth para dar uma volta pelo ambiente a fim de se refrescar por permanecer tanto tempo em uma mesma posição, revela-se uma cena cômica, mesmo na obra original, pois se percebe o ciúme da Srta. Bingley, no que se refere a Darcy e Lizzy. Contudo, na trama do escritor americano, tal imagem é reforçada por uma explicação elaborada pelo narrador sobre a resistência de Elizabeth. A cena se inicia com o convite de Caroline:

- Srta. Eliza Bennet, deixe-me persuadi-la a seguir meu exemplo. Venha caminhar pela sala. Asseguro à senhorita que se sentirá mais descontraída, depois de ficar sentada tanto tempo numa mesma posição.

Elizabeth não tinha necessidade nenhuma de descontrair - certa vez, haviam 
exigido que se mantivesse plantando bananeira por seis dias sob o sol escaldante de Pequim (Grahame-Smith, 2010a, p. 45).

Mesmo na trama original, Elizabeth não possuía todas as delicadezas e requintes que damas, como a Srta. Caroline Bingley, apresentavam. No entanto, imaginar a Srta. Bennet de pernas para o ar, durante seis dias, certamente revela a comicidade com que os zumbis são inseridos na obra. Ainda no que se refere às habilidades e técnicas de combate, destaca-se o episódio no qual o Sr. Darcy pede a Elizabeth que aceite sua mão e o tome como esposo. Depois de uma conversa que se transformou em discussão na qual Darcy afirma que ama Elizabeth mesmo contra sua razão e diante da inferioridade de nascimento da moça, a guerreira, depois de erguer as saias acima dos tornozelos, coloca-se novamente "na posição do grou, que considerou adequada para aquele ambiente tomado de móveis" (Grahame-Smith, 2010a, p. 149). Darcy mal pôde compreender a recusa da moça, "pois Elizabeth logo o atacava com uma série de chutes, forçando-o a responder com a defesa da lavandeira bêbada" (Grahame-Smith, 2010a, p. 149 - grifo do autor). É inevitável tentar imaginar em que se constitui tal golpe de defesa, assim como é impossível conter uma gargalhada diante de tal perspectiva. Até mesmo o grifo do autor permite que se faça tal análise, uma vez que destaca a cena.

Na sequência, a moça acerta Darcy com um golpe que o atira contra o console de pedra da lareira e, em meio às discussões sobre o fato de Darcy ter separado o Sr. Bingley de Jane, a seguinte cena se dá: "ele varreu os pés dela do chão com uma rasteira, enquanto, num salto, colocava-se de pé. Elizabeth foi bastante rápida para evitar que ele ficasse em vantagem e logo estava de novo ereta, brandindo o atiçador contra ele com renovado vigor" (Grahame-Smith, 2010a, p. 151). Adiante, ao discutirem o caso do Sr. Wickham, que supostamente teria sido prejudicado pelo Sr. Darcy, o cavalheiro falava "ao mesmo tempo em que pressionava o indicador contra o pescoço dela." (Grahame-Smith, 2010a, p. 152). Elizabeth, por sua vez, "sentia a cólera que crescia a cada instante; ainda assim, como Darcy a acuou contra uma parede, esforçou-se ao extremo para manter a compostura" (Grahame-Smith, 2010a, p. 152). Novamente percebe-se que a distinção de sexo entre Elizabeth e o Sr. Darcy não é levada em consideração e ambos lutam para defender suas vidas. Tal igualdade fica mais evidente quando se verifica que a luta foi iniciada pela moça. 
As descrições do embate entre o casal revelam-se cômicas, por pensar-se em uma dama e um cavalheiro, que provêm da alta sociedade inglesa, resolvendo seus conflitos de modo rude e selvagem, mesmo considerando-se que Eliza proveniente de uma família inferior - fora quem iniciara a briga. Além disso, ao se concluir a leitura da obra e se verificar que o casal contrai matrimônio, uma releitura da cena de luta deixa-a ainda mais ridícula, pois, mesmo tendo passado por inúmeros treinamentos orientais que os possibilitaram desenvolver a paciência e o autocontrole, ambos esquecem-se de suas origens e de seus mestres e resolvem a desavença aos chutes e pontapés.

Para encerrar, considera-se relevante observar dois elementos extratextuais que contribuem para a constituição da coerência da obra, uma vez que expressam o horizonte axiológico do autor. O primeiro constitui-se naquilo que Vic, do website Jane Austen's World, caracteriza como "ilustrações grosseiras, mas bem desenhadas" (Vic, 2010). Já o segundo constitui-se em questões sugeridas como um "guia de discussão para leitor" (Grahame-Smith, 2010a, p. 317). No que concerne às imagens, verifica-se que elas representam algumas das passagens mais relevantes da trama e, quase que em sua totalidade, referem-se aos zumbis. As descrições dos embates entre humanos e mortos-vivos que já provocam o riso são complementadas por desenhos de zumbis partidos ao meio, cérebros e entranhas expostos, facas atravessando olhos e bocas despedaçadas abocanhando cérebros. $\mathrm{O}$ traço irregular e as feições exageradas, mesmo daqueles que estão ainda vivos, não permitem o compadecimento, ao contrário, impulsionam a expressão do cômico.

Ao final da obra, encontra-se o segundo elemento - as questões de análise para o leitor - que abordam posicionamentos bastante distintos a respeito da trama. Observa-se que tais perguntas foram elaboradas como parte constitutiva da obra e não como algum produto de revisão e reedição posterior, uma vez que o volume analisado é da primeira edição. As dez perguntas referem-se a personagens como Elizabeth, o Sr. Collins, o Sr. Bennet e Wickham e orientam o leitor a pensar acerca deles a partir de polêmicas. Como exemplo, pode-se tomar a questão de número cinco:

5. Devido à impetuosa independência, devoção ao exercício e predileção por botinas, alguns críticos consideraram Elizabeth Bennet "a primeira lésbica literária". Você considera que, para esses autores, isso significa que ela seja gay? Caso seja 
assim, como a guinada sáfica serviria para exemplificar as relações de Elizabeth com Darcy, Jane, Charlotte, Lady Catherine e Wickham? (Grahame-Smith, 2010a, p. 318)

Observa-se que o autor se utiliza do discurso formal e institucionalizado da crítica literária para revelar seu horizonte axiológico acerca dos críticos literários. Suas questões demonstram uma sátira aguda àqueles que se ocupam com tal tipo de análise. No caso do romance, Grahame-Smith parece ter se antecipado às possíveis críticas que receberia com a publicação do romance. A questão de número seis aborda a temática do casamento e não só alfineta os prováveis críticos da trama, mas até mesmo Jane Austen quando afirma que "alguns críticos sugeriram que os zumbis representam a visão dos autores sobre o casamento", que para eles o matrimônio é "uma infindável praga que absorve a energia vital das pessoas sem, contudo, matá-las" e, em seguida solicita a opinião do leitor quanto ao simbolismo dos não mencionáveis (Grahame-Smith, 2010a, p. 318). Parece que o autor utiliza a própria pergunta para responder àqueles que talvez pudessem estabelecer tal relação entre os zumbis e o casamento e o questionar.

Finalmente, observa-se que a análise do contexto e da produção de Orgulho e preconceito e zumbis revela que a sociedade contemporânea vive um novo momento no que concerne à produção artística em geral. A internet coloca ao alcance de seus usuários uma infinidade de possibilidades, tanto no que tange à criação quanto à recepção de produtos artísticos, especialmente no que se refere aos jovens, grupo que tem mais afinidade com as transformações tecnológicas. Consumidores comuns possuem acesso a mecanismos de criação que Ihes permitem elaborar produções mashup, nas áreas da música e do vídeo e difundi-las através da rede mundial de computadores, com a oportunidade de dialogar acerca dos trabalhos, reelaborá-los, recriá-los, reformatá-los. Nesse sentido, verifica-se uma maior liberdade para que se exponham opiniões, críticas e conceitos.

Constatou-se que o contexto supracitado abre espaço para que se ouse recriar romances clássicos das formas mais inusitadas, com a inserção de vampiros, mutantes, monstros e macacos, sem que se fique ancorado apenas naquilo que os grandes catedráticos manifestarão a respeito, uma vez que a aceitação dessas obras se dá em um meio online ou, pelo menos, por indivíduos habituados à lógica do meio online, que visualizam a questão da produção artística 
sob a ótica da liberdade da criatividade. Assim, vê-se como viável a produção de um romance que insere zumbis em uma trama do período regencial inglês, tão popular exatamente por suas características do contexto da Regência e da sagacidade de sua escritora, sem que se possa afirmar que tenha havido desrespeito ao clássico, conforme Grahame-Smith comenta (2010c), e que, ao mesmo tempo, aproxime leitores jovens contemporâneos das obras clássicas. 


\section{Referências Bibliográficas}

AUSTEN, Jane. Pride and prejudice. London: Bounty Books, 2009.

BAKHTIN, Mikhail. Problemas da poética de Dostoievski. Trad. Paulo Bezerra. Rio de Janeiro: Forense-Universitária, 1981.

. Questões de literatura e de estética: a teoria do romance. 2a. ed. Trad. Aurora Bernardini et alli. São Paulo: Hucitec, 1990.

. Marxismo e filosofia da linguagem. 8ª . ed. Trad. Michel Lahud e Yara Frateschi Vieira. São Paulo: Hucitec, 1997.

COLOMER, Teresa. A formação do leitor literário. Trad. Laura Sandroni. São Paulo: Global, 2003.

GRAHAME-SMITH, Seth. Orgulho e preconceito e zumbis. Trad. Luiz Antonio Aguiar. Rio de Janeiro: Intrínseca, 2010a.

GRAHAME-SMITH, Seth. Entrevista. Disponível <http://thevarsity.ca/articles/24868>. Acesso em 15 de out. 2010 (2010b).

GRAHAME-SMITH, Seth. Entrevista ao Authors@Google. Disponível em <http:// www.youtube.com/watch?v=mLquizMt_BU>. Acesso em 12 de nov. 2010 (2010c).

JENKINS, Henry. Convergence Culture: where the old and new media collide. New York: NYU, 2006.

. Confronting the challenges of participatory culture: media education for the21st Century. Disponível em: <digitallearning.macfound.org/.../JENKINS _WHITE_PAPER.PDF.> Acesso em 18 de dez. 2010.

LADD, John. Dawn of the literary mashup. Disponível em <http://www. escapeintolife.com/essays/literary-mashup/>. Acesso em 11 de out. 2010.

SANTANA, Mauricio. Orgulho E Preconceito (E Zumbis): o diálogo entre o cânone e a narrativa pós-moderna. 134p. Dissertação (Mestrado em Teoria Literária) - Centro Universitário Campos de Andrade. Curitiba, 2012.

VARGAS, Maria Lúcia B. O fenômeno fanfiction: novas literaturas em meio eletrônico. Passo Fundo: Ed. Universidade de Passo Fundo, 2005.

VIC. Pride and Prejudice and Zombies: review of a high concept parody. Disponível em http://janeaustensworld.wordpress.com/2009/04/04/pride-and-prejudice-and-zombies-a-review-of-a-high-concept-parody/. Acesso em 23 de nov. 2010 